\title{
Analysis of Problems and Solutions of 'Subway' in the Chinese Catering Market from the Perspective of Design Thinking
}

\author{
Yi Wang \\ Beijing Jiaotong University, 100044, China \\ 19724027@bjtu.edu.cn
}

\begin{abstract}
With the further advancement of economic globalization, trade between countries has been strengthened, and cultural exchange and collision between countries have long been commonplace. Since China's reform and opening up, overseas culture has continuously been imported into the Chinese culture and catering market. The well-known American fast-food KFC is a successful example of enterprise localization in China. The overseas fast food industry will always encounter many problems when settling in China, such as low product popularity and insufficient product localization, which have led to the failure of the fast-food company's promotion in Chinese catering. In China, with the development of the economy, people's living standards are also improving. Young people in Contemporary Chinese society are more tolerant of foreign culture, foreign catering and foreign customs. More and more young people will choose to go to Western restaurants, cafes and other places in their spare time. This essay selects the famous American fastfood Subway as the protagonist; and discusses challenges that Subway faced in China from the perspective of design thinking. In addition, this essay will also provide feasible solutions for Subway from the perspective of designers.
\end{abstract}

Keywords: Subway; American Fast Food; Restaurant; Catering Market; Product Localization.

\section{Introduction}

As a fast-food enterprise from the United States, Subway is famous for its 'health and fresh' sandwiches, and it has a high reputation and tens of thousands of chain stores all over the world. As Subway company stated on their official website, as of June 2017, Subway had about 45000 stores worldwide and distributed in more than 100 countries. In terms of the number of stores, whether from the global level or just looking at the American market, Subway can be considered a successful chain fast-food model. However, it is this fashionable chain restaurant has encountered obstacles when developed in the Chinese catering market. As the first batch of American fast food to enter the Chinese market, Subway has developed in the Chinese market for more than 20 years since it first came to China in 1995. During the past 20 years, Subway has been in an awkward position among many catering chains in China. Although Subway is also well-known in China, it seems that people are not keen to buy Subway's sandwiches when they are hungry. Therefore, what causes the dilemma of Subway's marketing in China? This essay will first take Chinese Subway restaurant to compare with the overseas Subway restaurant, to discover the problems of Subway in China's catering market. In addition, this essay will analyse the problems of Subway's marketing strategy from the perspective of 'design thinking', then provide possible solutions to Subway.

\section{Existing Problems of Subway in the Chinese Market}

According to Macinnis and MacInnis (2008) has stated in their book "Consumer Behavior", "Consumers' age, gender, occupation, region, living habits and economic status are all major factors affecting consumers' purchasing power." Subway, as an American sandwiches chain store, is primarily famous for its original American taste sandwiches. In almost all countries, Subway supplies bread, all kinds of vegetables, sauces and cooked meat products for customers to choose from. That is to say, making a Subway sandwich need customers themselves to pick up their favorite bread, vegetables, meats and decide to add what kind of sauces based on their taste. In America and most European countries, people already seem to be familiar with this way. Especially for most young 
Americans, spending a few seconds buying a 'vegetable thing' is a completely quick and healthy way for them (Buzalka, 2013).

However, the same situation does not apply to the Chinese catering market. In China, most people seem not interested in buying a 'Subway' to allay their hunger. Compared to Subway, most Chinese customers prefer to choose traditional Chinese restaurants or just go to KFC and McDonald's. Therefore, what is the reason that leads Subway to an awkward situation like that? As Junginger (2008) has demonstrated, customers have different needs; ignoring customers' needs will cause the loss of the customer base. What are the problems with Subway? Subway has entered and stationed in China for more than 20 years, but it always sticks to making 'original American taste sandwiches', which may fail to meet the Chinese customers' taste. Talking about dietary habits, the difference between Chinese and Westerners eating habits can be a mere platitude. However, Subway seems like missed this point. It did not localize and innovate its products based on the appetite of the Chinese people. Therefore, the flavor of Subway's sandwiches has become a reason that Subway is not that popular with Chinese customers.

Regarding the taste of Subway's products, compared with the other western fast food such as KFC, Subway obviously lacks publicity in the Chinese market. As Hillgren and Bjögvinsson (2012) stated, "Effective publicity is even more attractive than good products. Organizations need to grasp the pain points of users and make users accept their products through publicity." For now, it seems like the most significant challenge that Subway faces is that 'Subway is not well known in China'. Therefore, if Subway wants to have better development in China, it needs to focus on solving the problem of its 'low popularity'. In China, KFC has made great efforts in its publicity. Whether in TV advertising or street posters, KFC's product promotion can be seen anywhere. In terms of product publicity, Subway is apparently inferior to KFC. In more than 20 years since Subway entered the Chinese catering market, its products have never appeared in TV advertisements, and it seldom advertises its products on the Internet. Moreover, as a 'fast food restaurant', Subway indeed targeted young people, but it seems to ignore some characteristics of young Chinese consumers. Although young people may be curious about Subway's original American sandwiches, a 40 yuan 6-inch sandwich is not a low cost for most Chinese students and office workers. Inadequate publicity, relatively high price, inconspicuous stores and excessively 'American style's taste', without exception, these factors have become the reasons that Subway is not so popular in China.

\section{Possible Solutions to Subway from the Perspective of Design Thinking}

Through research, some of the existing problems that Subway are facing can be analyzed. However, finding problems is only one aspect; what is more important is how organizations define their problems and then solve them (Brown, 2009). Based on the previous analysis, it is not hard to find out a big challenge Subway faces: 'Subway has a relatively low popularity in China and its business model does not adapt to the Chinese market'. Here, this essay will be based on Chinese people's habits and customs to give possible solutions to Subway through the perspective of design thinking.

According to Brown (2008) has stated in his book "Design Thinking", "The driving force of innovation is to thoroughly understand people's potential demand through direct observation, for example, the manufacturing, packaging, marketing, and support methods of specific products they like or dislike." From Brown's viewpoint, observing and understanding customers' needs is a vital part of the organization. In America, Subway is doing well in understanding customers' needs. For example, America's Subway stores have launched the extra-large sandwich (Giant Sub) and more kinds of cheese, cooked meat products and sauces based on American's taste (Taylor, 2008).

According to the introduction on Subway's official Website (America area), in the US, Subway mainly supplies its featured products (sandwiches, salads, signature wraps), breakfast, kids' meal, free carbonated drinks, desserts and snacks (mostly are Lay's Potato Chips and large cookies) for its customers, and the variety of food that Subway provided is also very satisfying. 
However, compared to America, Chinese Subway stores seem less than satisfactory. In China, customers can only order sandwiches and salads in most Subway stores, and this is undoubtedly not conducive to subway's marketing in the Chinese market. Thus we can see that the United States Subway merchants have a good insight into the demand of American customers, while Chinese Subway merchants still need to improve. Therefore, how can Chinese Subway stores solve their problems?

Empathy for consumers is crucial for enterprises to win customers' recognition (Castellion, 2010). As we analyzed earlier, traditional American sandwiches are not 'appreciated' by Chinese people's appetite, and that also became a reason that leads Subway not popular in China. 'Organizations should develop new products to meet the demand of consumers based on the volatility change of market' (Bason, 2010). The Chinese catering market has never lacked delicious fast-food restaurants, and that is not easy for Subway to stand out in such an environment. To better make their food satisfy Chinese people's appetite, Chinese Subway agents need to have a deep insight into Chinese customers eating habits, and that need those Chinese agents to have a strong empathy with their customers. For example, Americans may think cold vegetables with sweet sauce is a healthy eating choice. However, most Chinese people who usually eat stir-fry might not be in favor of the taste of raw vegetables. Therefore, how can Subway do for its Chinese customers? Based on Chinese people's dietary habits, it is worth it for Subway to try to 'innovate' some 'Chinese taste' sandwiches. For example, Subway can add ingredients from traditional Chinese dishes into its sandwiches, and then the customers may get the 'Kung pao chicken sandwich', 'Beijing roast duck sandwich' and 'Mapo Tofu flavor sandwich', even the 'Hot Pot flavor sandwich'. On the one hand, if subway can creatively launch some 'Chinese taste' sandwiches, it will be a surprise for most Chinese customers, because Subway has always stuck to its original American taste sandwiches. On the other hand, as Macinnis and MacInnis (2008) stated, 'novel products can always attract customers' attention', possibly the new 'Chinese taste sandwiches' can promote Chinese consumers' consumption of Subway. By considering from the perspective of customers, enterprises can better insight customers' preferences, and it is important for Subway to have empathy with its customers. Moreover, it is also important for Subway to have the continuous innovation ability, so that it can always launch new products based on its customers' demand.

According to Agarkova's (2012) view, effective publicity is often more important because it determines whether the products will be concerned. Apart from the flavor of Subway's foods, compared to the other chain fast-food enterprises, the efforts that Subway put in publicity are obviously not enough. As we mentioned earlier, relatively low popularity should be the biggest challenge that Subway faces. China's Internet industry has been developing rapidly in recent years, and it is not hard to find that many businesses use WeChat, Tik-Tok, and other network means to propagate their products, not to mention TV advisement. To solve this problem, Subway can put more effort to propagate its dishes on the Internet media. In China, Subway has its own 'Chinese Subway Official Website'. However, compared to KFC's publicity construction, Subway still has a lot improve space. Based on this problem, an area's (for example, Beijing area) Chinese Subway agents can work together to ideate special activities for customers. For example, Chinese people value 'feelings', so that it can be a good choice for Chinese Subway agents to design souvenirs and activities (for example, discount activities) from Chinese traditional festival's customs.

In America, Subway put itself onto a 'cheap fast-food' position, and it also did not pay much attention to its storefront decoration. Therefore, since Subway first came to the public's eyes, it has always consisted of its green and yellow appearance decoration, which may lead Subway does not looks like a 'restaurant'. In the US, eating a sandwich as a quick lunch choice is well received by the public, and Subway is also very popular around America and most European countries. However, in China, people may not be that familiar with sandwiches, and this can be specifically reflected in customers who do not know how to collocate different ingredients when they first come to Subway. People's unfamiliarity with Subway is a problem that Subway faces. Therefore, how can Subway solve this problem? As Koomsap (2013) stated, "Businesses should give customers enough indication to show what their product might be, so that customers can make their own decision at the first time." 
From the perspective of customers, if Subway can put a 'sandwich symbol' onto its signboard, that will give the customers a direct indication that 'Subway' is a sandwich store. Therefore, how can Subway do for its customers? Designers usually make quick and straightforward prototypes to test their thinking and so do achieve the ideal effect (Buchanan \& Margolin, 1995). To quickly make a signboard printed with a sandwich or launch a 'Subway sandwich mascot' are all excellent choices. By quickly building a prototype, Subway can quickly access its customers' responses, thus providing better services. Moreover, making quick and straightforward prototypes is also a very economical solution.

Talking about 'build prototype', it should be a good choice for Subway to make prototypes for empathy with its customers. Moreover, through creating quick and simple prototypes, there are many aspects that Subway can try to make changes. As Lockwood (2010) claimed in his book, "Organizations need frequently innovate their strategy to catch up with times changes." In recent years, many western fast-food restaurants have made many localization improvements in their marketing strategy, which is embodied in adding traditional Chinese elements to their decoration and products. For example, many Chinese KFC stores have made some changes to their appearance decoration, making them look more likely a 'Chinese Style Western Restaurant'.

"Unique decoration style, comfortable and warm interior design can always satisfy users, enterprises should be based on their service sectors to design suitable decoration environment for their customers (Liu \& Kan, 2020)." Similarly, as the American fast-food store, Subway can learn from the other fast-food restaurants (for example, KFC and McDonald's) to make some changes. For example, making its appearance decoration and interior design more 'Chinese style', using internet approaches to propagate its new products, or just dividing an area as children's playground like what KFC and McDonald's did. To quickly try these ways are the advantages that 'build prototype' can bring to Subway, because through build relatively prototypes can help Subway to quickly insight customers' pain points and needs. For example, build a 'children's park' prototype in Subway to observe if it is suitable and collect customers' feedback. However, building prototypes is only one aspect, do change or not is still depends on Subway's own decision.

As far as Subway is concerned, there are still many challenges that Subway are facing. As Behn (1995) stated in his book, "Organization's culture is determined by people, and people would directly influence the innovation capacity, that is all because people are the carriers of the imaginations and practices." In order to make products be more 'hominization', designers usually stressed 'HumanCentered Design' (Carolyn, 2010). As a multinational fast-food company, Subway can try to focus on people's daily lives, insight people's needs from different countries, ages and occupations, so as to make its products be more close to different customers' demands. Therefore, how can Subway make changes? Subway can expand its customer target to people of all ages, whether office workers, students, or children. For example, Subway can develop products based on different ages and different professionals' needs. For those office workers who are always in a hurry, Subway can try to provide them with faster services, like directly providing them with prepared sandwiches and salads, so that those office workers who are in a hurry can buy a sandwich at ease. Similarly, preparing breakfast for those office workers and students might also be a good choice for Subway.

For children, it is also a good choice to provide children with children's meals. Besides, it is not hard for Subway to make smaller and lovely sandwiches for children, just like other countries did. More importantly, if Subway has the 'children's meal' choice, probably those Chinese parents who usually go to work in a busy, may just order a meal for their child from Subway. This is also a way to promote product selling for Subway. What's more, Chinese Subway agents can also take children as their target customers. By doing so, there can be more new ideas for Chinese Subway to develop more new dishes. In addition, there are still many aspects that Subway can do, but possibly the most significant challenge that Chinese Subway are facing is still that 'Subway need to improve its popularity in China'. 


\section{Conclusion}

Although Subway has many aspects that need to improve, it is still one of the most successful fastfood companies around the world. As Martin (2009) has stated, "When facing challenges, enterprises should not only just find out their problems and make changes, but also should draw lessons from the failure cases of other enterprises". Through research, in China, Subway's biggest challenge should be the 'relatively low popularity and the inappropriate business mode'. In response to this challenge, this essay uses design thinking methodologies to provide possible solutions to Subway. Firstly, this essay gives a basic introduction to the fast-food company Subway, including the background introduction of the company and its development situation in the Chinese catering market.

In the second part, based on the research materials, this essay analyzed the existing problems that Subway are facing to give the point of view, which is the main challenge that Subway faces: 'Subway has a relatively low popularity in China and its business model does not adapt to the Chinese market'. Then, in the third part, based on the design thinking methodologies, this essay from the perspective of empathy to provide possible solutions to Chinese Subway. Moreover, this essay also proposed that quickly building and testing prototypes might be a good way for Chinese Subway's agents to make changes. Besides, this essay also put forward some possible solutions from other perspectives.

For now, solving these known problems is a good chance for Subway to make changes. However, to have better development in the Chinese market in future is also essential to Subway. Based on Martin's point of view, in the aspect of getting customers approval, Subway still has a long way to go, and that needs Subway to continuously learn from the other successful catering companies and make changes in now and future. Hopefully, Subway can have better development in China.

\section{References}

[1] Agarkova, A. (2012). Economic Ground of Efficiency of Publicity Campaign, 1 (10), 275-277.

[2] Behn, D. (1995). The Big Questions of Public Management. Public administration review, 55(4), 313 324.

[3] Bason, C. (2010). Leading Public Sector Innovation: Co-creating for a better society. Bristol, UK: The Policy Press.

[4] Bjögvinsson, E. \& Hillgren, P. Eds. (2012). Design Things and Design Thinking: Contemporary Participatory Design Challenges. Design issues, 28(3), 101-116.

[5] Brown, T. (2008). Design Thinking. Harvard business review, 86(6), 84-92.

[6] Brown, T. (2009). Change by Design: How Design Thinking Transforms Organizations and Inspires Innovation. NY, USA: Harper Collins.

[7] Buchanan, R. \& Margolin, V. Eds. (1995). Discovering Design: Explorations in Design Studies. Chicago, IL: University of Chicago Press.

[8] Buchanan, R. (2004). Management and Design: Interaction Pathways in Organisational Life. In R. Boland \& F. Collopy (Eds.), Managing as Designing (pp. 54-63). Stanford, USA: Stanford University Press.

[9] Buzalka, M. (2013). Do Teens "Eat Fresh" at Subway? Food Management. Retrieved November 1, 2021, from https://www.food-management.com/blog/do-teens-eat-fresh-subway.

[10] Castellion, G. (2010). The Design of Business. Why Design Thinking Is the Next Competitive Advantage by Roger Martin and Design-Driven Innovation: Changing the Rules of Competition by Radically Innovating What Things Mean by Roberto Verganti: Book Reviews. The Journal of product innovation management, 27(6), 931-935.

[11] Cross, N. (2001). Designerly ways of knowing: design discipline versus design science. Design Issues, 17(3), 49-55.

[12] Carolyn, T. (2010). Empathy in the global world an intercultural perspective. London, UK: SAGE.

[13] Junginger, S. (2008). "Product Development as Vehicle for Organizational Change". Design Issues, Special Issue: Organizational Change, 24(1), 26-35. 
[14] Koomsap, P. (2013). Design by customer: concept and applications. Journal of intelligent manufacturing. 24 (2), 295-311.

[15] Liu, Hanbing. \& Kan, Yuyue. (2020). Business model innovation of Qingdao Youzhu Decoration Company. EDP Sciences. 214(1), 02046.

[16] Lockwood, T. (2010). Design thinking integrating innovation, customer experience and brand value. New York: Allworth Press.

[17] Macinnis, H. \& Maclnnis, D. (2008). Consumer Behavior. Mason, Washington: Cengage Learning.

[18] Martin, R. (2009). The Design of Business. Why Design Thinking is the next competitive advantage, Boston, Massachusetts: Harvard Business Press.

[19] Morris, S. (2006). Interior decoration a complete course. Delhi: Global Media.

[20] Taylor, K. (2018). Subway's 'mystery meat' and 'mushy and rotten vegetables' destroyed the 'Eat Fresh' advantage it spent years building. Business Insider. Retrieved October 28, 2021, from https://www. businessinsider. com/subway-food-hurts-reputation-fails-to-keep-up-with-trends-2018-1. 